\title{
PENERAPAN GROUP ANGER MANAGEMENT DAN PROBLEM SOLVING TRAINING DALAM MENURUNKAN AGRESI PADA REMAJA DI LPKA
}

\author{
Gracia Ivonika ${ }^{1}$ dan Roslina Verauli ${ }^{2}$ \\ ${ }^{1}$ Program Studi Psikologi Profesi Jenjang Magister, Universitas Tarumanagara, Jakarta \\ Email: graciaivonika@gmail.com \\ ${ }^{2}$ Fakultas Psikologi, Universitas Tarumanagara, Jakarta \\ Email: roslinav@fpsi.untar.ac.id
}

Masuk : 03-05-2019, revisi: 26-04-2020, diterima untuk diterbitkan : 26-04-2020

\begin{abstract}
Aggression is a behavior that includes intention to hurt others both physically and psychologically. Some risk factors that play an important role in aggression are lack of anger control and problem solving. Anger management training and problem solving training can improve the ability to manage and express anger in a socially competent behavior, and solve problems with the right considerations without involving aggressive behavior. Problem solving skills are important for adolescents. This study aims to determine whether the application of group anger management and problem solving training can reduce aggressive behavior among male adolescents in LPKA. The five study participants had records of aggressive behavior from young age to adolescence and often resolved problems through aggressive behavior. The anger management and problem solving training group lasted for 8 sessions. This study uses mixed method one group pre-test post-test design. Evaluations were conducted using Draw-A-Person Test, $B A U M$, and Aggressive Behavior Scale before and after the intervention. The results of this study indicate that the five participants showed a decrease in aggressive behavior scores. Changes between pre-test and post-test of DrawA-Person Test and BAUM can be seen from changes in drawing of person made by participants based on the size, location of the drawing, shape, lines, and attributes of the drawing.
\end{abstract}

Keywords: Anger management, problem solving, aggressive behavior, adolescents, Correctional Institution

\begin{abstract}
ABSTRAK
Perilaku agresi adalah suatu kategori perilaku yang ditunjukkan dengan niat untuk menyakiti orang lain baik secara fisik maupun secara psikologis. Beberapa faktor risiko yang memainkan peran penting dalam perilaku agresi adalah kurangnya kemampuan pengendalian kemarahan dan pemecahan masalah. Pelatihan anger management dan problem solving training dapat meningkatkan kemampuan mengelola dan mengekspresikan kemarahan dalam bentuk perilaku yang kompeten secara sosial, serta memecahkan masalah dengan pertimbangan yang tepat tanpa melibatkan perilaku agresi. Kemampuan pemecahan masalah juga merupakan komponen dalam keterampilan hidup yang penting bagi remaja. Penelitian ini bertujuan untuk mengetahui seperti apakah penerapan group anger management dan problem solving training dapat menurunkan perilaku agresi pada remaja pria di LPKA. Kelima partisipan penelitian ini memiliki latar belakang perilaku agresi sejak usia sekolah hingga remaja dan seringkali menyelesaikan masalah dengan melibatkan perilaku agresi. Group anger management dan problem solving training yang dijalankan oleh partisipan berlangsung selama 8 sesi. Penelitian ini menggunakan mixed method one group pre-test post-test design. Evaluasi dilakukan menggunakan Draw-A-Person Test, BAUM, dan Skala Perilaku Agresi sebelum dan sesudah intervensi dilaksanakan. Hasil penelitian ini menunjukkan bahwa kelima partisipan mengalami penurunan skor perilaku agresi. Perubahan dalam evaluasi pre-test dan post-test Draw-A-Person Test dan BAUM dapat dilihat dari perubahan gambar orang yang dibuat oleh partisipan berdasarkan aspek ukuran, letak gambar, bentuk, coretan garis, dan atribut pada gambar.
\end{abstract}

Kata Kunci: Anger management, problem solving, perilaku agresi, remaja, Lembaga Permbinaan

\section{PENDAHULUAN \\ Latar Belakang}

Perilaku agresi pada remaja dianggap sebagai topik yang semakin penting untuk diteliti, karena banyak penelitian telah menunjukkan bahwa perilaku agresi dapat mewakili faktor risiko untuk beberapa dampak yang destruktif, termasuk putus sekolah, penyalahgunaan zat dan aktivitas kriminal terutama pada remaja (Babore, Carlucci, Cataldi, Phares, \& Trumello, 2016). Buss dan Perry (1992) menyatakan perilaku agresi sebagai perilaku yang ditunjukkan dengan niat untuk 
menyakiti orang lain baik secara fisik maupun secara psikologis. Meskipun dapat terjadi di seluruh lapisan masyarakat, remaja merupakan kelompok yang sangat rentan untuk melakukan perilaku agresi. Sebagian besar remaja berhasil mengatasi masalah perilakunya dan tidak menjadi perilaku kriminal, Sebaliknya, remaja yang tidak berhasil mengatasinya cenderung mengembangkan perilaku antisosial dan kekerasan ketika dewasa (Papalia \& Martorell, 2014).

Cillessen, Lansu, dan Berg (2014) menjelaskan bahwa remaja dengan status yang rendah cenderung menunjukkan agresi permusuhan (hostile aggression) yang dipahami sebagai agresi yang impulsif, tidak dipikirkan, muncul dari kemarahan dan memberikan cedera pada orang lain. Sedangkan, agresi instrumental lebih ditunjukkan pada remaja dengan status tinggi. Agresi instrumental dapat dipahami sebagai agresi dengan dorongan atau motivasi yang direncanakan untuk mencapai beberapa tujuan. Remaja cenderung menampilkan bentuk agresi yang terlihat (overt aggression), yaitu tindakan konfrontasi dari agresi fisik seperti perkelahian fisik, bullying, penggunaan senjata tajam dalam tindakan kejam, dan menentang aturan sosial dengan sengaja (Connor et al., 2004). Perilaku agresi yang terjadi dikalangan remaja, tidak terlepas dari pengaruh kepribadian seseorang. Salah satu faktor yang berperan timbulnya perilaku agresi adalah jenis kelamin. Remaja yang berjenis kelamin laki-laki mempunyai kecenderungan untuk berperilaku agresi lebih tinggi dan terlibat dalam agresi fisik (Santrock, 2011).

Faktor yang menyebabkan terjadinya perilaku agresi pada remaja yaitu faktor internal maupun faktor eksternal. Faktor internal tersebut meliputi perasaan frustasi, gangguan pengamatan dan tanggapan remaja atas situasi, gangguan berpikir dan inteligensi remaja, serta gangguan perasaan/emosional remaja. Faktor eksternal meliputi faktor media, pengaruh alkohol dan narkoba, serta faktor lingkungan, seperti keluarga, sekolah, dan tempat tinggal (Kartono, 2011). Remaja mempunyai sifat yang cenderung lebih agresi, emosi tidak stabil, dan sulit menahan dorongan. Pada masa pubertas atau masa menjelang dewasa, remaja mengalami banyak pengaruhpengaruh dari luar yang menyebabkan remaja terbawa pengaruh oleh lingkungan tersebut. Hal tersebut mengakibatkan remaja yang tidak bisa menyesuaikan atau beradaptasi dengan lingkungan yang selalu berubah-ubah akan melakukan perilaku yang maladaptif, seperti contohnya perilaku agresi yang dapat merugikan orang lain dan juga diri sendiri (Silva, Soares, \& Oliveira, 2014). Relasi dengan teman sebaya tampaknya memainkan peran penting dalam perilaku agresi remaja. Menampilkan perilaku agresi dapat menjadi cara untuk mendapatkan popularitas atau status sosial yang tinggi dengan menunjukkan kekuatan atau kontrol. Tekanan teman dapat menyebabkan tingkah laku agresi karena takut terisolasi atau kehilangan kedudukan sosial (Liu, Lewis, \& Evans, 2012).

Salah satu pemicu yang umum dari perilaku agresi adalah emosi marah. Meskipun emosi marah merupakan sesuatu yang alamiah dan perlu untuk diekspresikan, namun seringkali marah yang tidak diekspresikan dengan tepat memiliki konsekuensi yang berpotensi merusak dan merugikan (Lok, Bademli, \& Canbaz, 2018). Beberapa studi menunjukkan perilaku agresi ini telah dianggap sebagai prediktor ketidaksesuaian remaja yang menunjukkan bahwa mereka juga berisiko tinggi untuk kesulitan mengelola emosi negatif, masalah psikologis, dan masalah relasi sosial dalam jangka pendek dan panjang Estévez, Jiménez, \& Moreno, 2018). Ketidakmampuan mengelola emosi negatif juga mengarahkan pada ketidakmampuan menyelesaikan masalah dengan tepat tanpa melibatkan perilaku agresi. Seringkali remaja dengan emosi yang cenderung tidak stabil (Santrock, 2011) menyelesaikan masalah dengan melibatkan agresi yang dianggap sebagai reaksi wajar sesuai situasi-situasi yang sering mereka lihat di lingkungan sekitar dan media (Merrill, Smith, Cumming, \& Daunic, 2016). Meskipun tidak secara eksplisit reaktif, pengaruh teman sebaya dalam jejaring sosial menunjukkan agresi adalah perilaku yang dapat diserap melalui 
pemodelan kontak yang melibatkan agresi oleh orang-orang sekitar, terutama teman sebaya (Faris \& Ennett, 2012).

Terkait dengan maraknya kasus kekerasan yang terjadi di Indonesia, setiap pelaku kekerasan tentu akan diproses secara hukum. Hal ini juga berlaku bagi pelaku yang masih berusia remaja, termasuk remaja di LPKA Tangerang. Agresi merupakan sesuatu yang sulit diubah tanpa bantuan intervensi (Krahe, 2013). Oleh sebab itu, anak didik di Lembaga Permbinaan Khusus Anak (LPKA) rentan untuk menunjukkan tingkat agresi yang tetap tinggi, baik selama di dalam Lapas maupun saat bebas. Perilaku agresi salah satunya dapat dikurangi dengan penanganan Anger Management. Dalam hal ini, anger management, didasarkan oleh teori sosial kognitif yang menjelaskan bahwa kemarahan yang tidak dapat dikontrol dengan baik dapat ditampilkan dalam bentuk agresi, sehingga individu tersebut perlu belajar kembali cara-cara mengurangi atau menahan amarahnya dengan mengamati atau mempelajari perilaku baru yang lebih positif (Down, Willner, Watts, \& Griffiths, 2010). Selain anger management, keterampilan pemecahan masalah juga dianggap sebagai keterampilan manajemen diri yang penting karena merupakan komponen dalam keterampilan hidup. Rendahnya kemampuan pemecahan masalah pada remaja telah banyak berhubungan dengan munculnya perilaku agresi. Kemampuan pemecahan masalah diperlukan bagi remaja untuk memecahkan masalah dengan tepat tanpa melibatkan agresi (Mirzaei, Meimandi, Mousavi, Raesi, \& Masoudi, 2016). Hal ini dikarenakan perilaku agresi yang tidak ditangani akan cenderung stabil bertahan dan dilakukan oleh remaja sebagai cara untuk menyelesaikan masalah hingga dewasa kelak (Krahe, 2013). Oleh karena itu, peneliti ingin memberikan intervensi kelompok dengan menggunakan anger management dan problem solving training kepada kelima anak ini agar dapat meningkatkan kontrol perilaku agresi yang ditampilkan oleh masing-masing anak dengan mampu mengontrol amarah dan memecahkan masalah dengan tepat. Intervensi kelompok diberikan dalam bentuk pelatihan sebagai salah satu bentuk pendekatan intervensi yang terbukti efektif pada target perilaku dan peningkatan keterampilan (Fredberg \& Brelsford, 2013). Dengan demikian permasalahannya "Apakah anger management dan problem solving training dapat menurunkan perilaku agresi pada remaja di LPKA?"

\section{METODE PENELITIAN}

\section{Partisipan}

Partisipan penelitian lima remaja laki-laki yang berpartisipasi dalam anger management dan problem solving training memiliki karakteristik sebagai berikut: (a) berada dalam tahapan usia remaja akhir (15-18 tahun), (b) merupakan anak didik LPKA (Andikpas) (c) memiliki latar belakang dan menunjukkan perilaku agresi secara verbal maupun fisik (d) dan memiliki skor IQ setidaknya mendekati rata-rata ke atas.

\section{Desain penelitian}

Penelitian ini menggunakan mixed method one group pre-test post-test design yang dilakukan dengan menggunakan wawancara semi terstruktur, serta alat ukur kala Perilaku Agresi, Draw-APerson, dan BAUM. Pada desain tersebut, dilakukannya pengukuran terhadap variabel terikat kepada partisipan dalam satu kelompok penanganan yang sama sebelum dan sesudah intervensi diberikan. Partisipan mengisi alat ukur Skala Perilaku Agresi, Draw-A-Person, dan BAUM. Lalu, partisipan menjalankan 8 sesi terapi kelompok anger management dan problem solving training. Setelah terapi kelompok selesai dijalankan, partisipan mengisi alat ukur Skala Perilaku Agresi, tes Draw-A-Person, dan tes BAUM kembali yang dianalisa untuk mengetahui perbandingan hasil sebelum dan sesudah pemberian intervensi. 


\section{Instrumen penelitian}

\section{Tes Grafis: Draw-A-Person dan BAUM}

Tes grafis dilakukan untuk mengetahui gambaran perkembangan kepribadian anak, emosi, dan perilaku. Selain itu, tes grafis juga digunakan untuk melihat indikasi agresi pada anak (Machover, 1949). Analisa gambar dilakukan berdasarkan beberapa prinsip interpretasi Ogdon (1974).

\section{Culture Fair Intelligence Test}

Cultural Fair Intelligence Test (CFIT) merupakan satu tes inteligensi non-verbal yang dikembangkan oleh Raymond B. Catell (1979). CFIT skala 3a dapat digunakan untuk individu antara usia 15 sampai 18 tahun. CFIT mengukur inteligensi individu yang mengurangi pengaruh dari kelancaran verbal, budaya, dan tingkat edukasi. Dengan menggunakan CFIT, fluid intelligence, yaitu inteligensi yang dipengaruhi oleh faktor biologi, dapat diketahui (Catell dalam Nenty \& Dinero, 1981). Hal tersebut dapat dilihat melalui bagaimana individu mampu mempersepsikan relasi pada bentuk dan figure yang dilihat olehnya. CFIT terdiri dari 48 item yang dikelompokkan dalam empat set di mana masing-masing set dibatasi dengan waktu pengerjaan yang berbeda.

\section{Skala Perilaku Agresi}

Skala Perilaku Agresi adalah satu instrumen yang dikembangkan Buss \& Perry dalam bentuk short-form (AQ-SF) oleh Bryan \& Smith (2011), dan telah diadaptasi oleh Irena (2014) untuk mengukur tingkat agresi. Instrumen ini terdiri dari 12 item pernyataan untuk mengukur empat dimensi dari agresi, yaitu agresi fisik; agresi verbal; kemarahan; permusuhan. AQ-SF menggunakan 6 pilihan jawaban dengan skor 1 untuk 'sangat tidak menggambarkan diri saya' dan skor 6 untuk 'sangat menggambarkan diri saya'. Cara skoring AQ-SF adalah dengan menjumlahkan total skor yang diperoleh. Tujuan dari penggunaan alat ukur ini adalah untuk mengukur perubahan tingkat agresi, maka total skor pada saat pre-test dan post-test digunakan sebagai tolak ukur perubahan yang terjadi. Skor reliabilitas alat ukur AQ-SF yang telah diadaptasi adalah .796 berdasarkan Cronbach's Alpha sehingga dapat dikatakan bahwa seluruh item dari kuesioner ini reliabel.

\section{Perlengkapan penelitian}

Selama melakukan penelitian, terdapat beberapa perlengkapan yang perlu dipersiapkan. Sebelum penelitian dilakukan, partisipan diberikan lembar informed consent. Selain itu, hal yang diperlukan untuk melakukan pretest dan posttest adalah lembar alat ukur Skala Perilaku Agresi, kertas HVS berukuran A4, pensil HB, dan penghapus. Pada saat terapi kelompok berlangsung, perlengkapan yang harus disediakan adalah kertas A3, karton, spidol, pensil warna, pulpen, kertas memo, laptop, video, lem, beberapa lembar kerja, dan reward poin keaktifan.

\section{Prosedur penelitian}

Peneliti pertama-tama melakukan screening kepada 50 Andikpas di LPKA Tangerang dengan menggunakan tes Draw-A-Person, BAUM, dan CFIT. Kemudian peneliti mendapatkan 5 orang siswa memiliki kecenderungan perilaku agresi. Berdasarkan hasil anamnesa dengan kelima partisipan diketahui bahwa kelima partisipan memang memiliki latar belakang perilaku agresi sejak usia kanak-kanak hingga remaja. Hal yang memicu perilaku agresi para partisipan adalah adanya suatu situasi atau orang yang mengancam atau mengganggu mereka, perasaan frustrasi, serta pengaruh lingkungan tempat tinggal dan kelompok pertemanan yang marak dengan perilaku agresi. Setelah itu, peneliti memberikan lembar informed consent untuk meminta kesediaan partisipan menjalani proses terapi kelompok. Lalu, partisipan diminta mengisi alat ukur Skala Perilaku Agresi untuk mengetahui tingkat agresi dari kelima partisipan. Selanjutnya, kelima 
partisipan menjalani terapi kelompok anger management dan problem solving training selama 8 sesi. Setelah selesai diberikan program intervensi, kelima partisipan mengisi kembali alat ukur state Skala Perilaku Agresi, tes Draw-A-Person, dan BAUM sebagai posttest. Hasil pretest dan posttest kemudian dibandingkan untuk mengetahui dampak dari program intervensi terhadap tingkat agresi dari kelima remaja.

\section{Pelaksanaan intervensi}

Metode intervensi kelompok diberikan dengan mengenalkan problem solving training dengan tujuan partisipan belajar menyelesaikan masalah tanpa melibatkan agresi. Selain itu, anger management juga diberikan untuk membantu partisipan mengelola kemarahan yang diharapkan dapat menurunkan kecenderungan agresi pada remaja laki-laki di LPKA Tangerang. Tahapan yang akan dilakukan pada saat terapi dirancang berdasarkan intervensi problem solving training dan anger management yang diterapkan oleh Mirzaei, et al. (2016) untuk meningkatkan kemampuan kontrol agresi pada narapidana. Mirzae, et al. (2016) menerapkan 6 sesi inti terapi, sedangkan peneliti menambahkan dua sesi tambahan yaitu sesi pembuka dan penutup (terminasi), sehingga menjadi 8 sesi terapi. Sesi pembuka diberikan bertujuan untuk membangun komitmen dan memberikan pemahaman yang seragam terkait proses terapi kepada setiap partisipan. Sedangkan sesi penutup ditambahkan untuk merangkum dan mengevaluasi proses terapi bersama seluruh partisipan.

Sesi pertama dimulai dari perkenalan kelompok, tujuan dan gambaran kegiatan terapi, serta membangun komitmen kelompok. Sesi kedua merupakan awal sesi inti yang merupakan pengantar dan perkenalan kemampuan pemecahan masalah, tujuan dan tahapan pemecahan masalah. Sesi ketiga dilanjutkan lebih mendalam memahami aplikasi pemecahan masalah dengan media video, diskusi kelompok, dan analisa. Sesi keempat bertujuan untuk membangun pemahaman partisipan mengenai amarah dan agresi, yaitu perbedaan dan kaitan keduanya, serta pemicu, perilaku, dan konsekuensinya. Sesi kelima dilanjutkan dengan pendalaman pemahaman tentang faktor serta konsekuensi dari amarah dan agresi melalui sharing dan self-analysis. Sesi keenam, partisipan diperkenalkan dan mencoba teknik-teknik kontrol amarah dengan role play serta brainstorming (relaksasi, bersikap asertif, dan self-talk). Sesi ketujuh, partisipan mencoba mengaplikasikan kontrol amarah dan pemecahan masalah dengan tepat dikaitkan dengan masalah atau pengalaman hidup mereka sebelumnya. Sesi kedelapan adalah sesi terminasi.

\section{HASIL DAN PEMBAHASAN}

\section{Evaluasi Draw-A-Person Test dan BAUM}

Secara umum, pada perbandingan pre dan post-test Grafis tampak beberapa perubahan positif menggambarkan penghayatan partisipan yang lebih positif tentang diri dan orang lain, peningkatan self-esteem, social self-concept, dan kontrol diri, serta menurunnya kecenderungan agresi. Perubahan partisipan tampak dari perubahan figur orang dan pohon yang digambar oleh para partisipan berdasarkan ukuran, letak, bentuk, arah, dan coretan garis. Hal-hal yang berubah pada post-test yang dibuat oleh partisipan termasuk mengecilnya ukuran gambar orang secara keseluruhan, letaknya lebih ke arah tengah kertas, hilangnya bentuk bagian tubuh yang tajam maupun aksesoris yang berkaitan dengan perilaku agresi (senjata dan pakaian tinju), mata yang lengkap dengan bola mata, beberapa bagian tubuh yang sebelumnya tidak terlihat menjadi terbuka, serta leher yang digambar lebih jelas. Pada hasil post test BAUM tidak tampak perubahan yang signifikan, namun beberapa partisipan memerlihatkan perubahan positif dari hilangnya shading dan ukuran gambar yang sebelumnya terlalu besar menjadi lebih kecil. 


\section{Evaluasi Skala Perilaku Agresi: Perbandingan Pre-Test \& Post-Test}

Total skor Skala Perilaku Agresi yang diperoleh kelima partisipan sebelum berpartisipasi dalam intervensi berbeda dengan total skor yang didapatkan setelah mengikuti 8 sesi intervensi. Total skor dari kelima partisipan mengalami penurunan.

Tabel 1. Skor Total Alat Ukur Skala Perilaku Agresi pada Pre-test dan Post-test

\begin{tabular}{cccc}
\hline & Pre-test & \multicolumn{2}{c}{ Post-test } \\
\hline Partisipan & $\begin{array}{c}\text { Skor Total Skala } \\
\text { Perilaku Agresi }\end{array}$ & Partisipan & $\begin{array}{c}\text { Skor Total Skala } \\
\text { Perilaku Agresi }\end{array}$ \\
\hline R & 42 & $\mathrm{R}$ & 39 \\
\hline NF & 46 & NF & 29 \\
\hline D & 46 & $\mathrm{D}$ & 37 \\
\hline A & 44 & $\mathrm{~A}$ & 36 \\
\hline F & 49 & $\mathrm{~F}$ & 37 \\
\hline
\end{tabular}

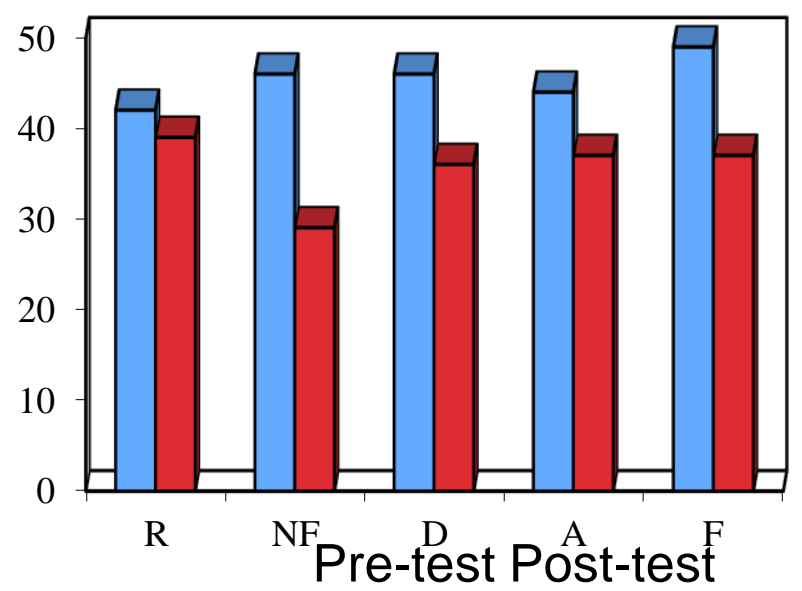

Grafik 1. Skor Total Alat Ukur Skala Perilaku Agresi Pre-test dan Post-test

Terjadi perubahan pada mean skor total Skala Perilaku Agresi partisipan penelitian pada posttest jika dibandingkan dengan skor pada saat pre-test (lihat Grafik 1). Rata-rata dari total skor alat ukur Skala Perilaku Agresi jika pre-test dan post-test dibandingkan mengalami penurunan skor. Partisipan menunjukkan kontrol diri yang lebih baik dan menjangkau relasi sosial dengan cara yang lebih positif dibandingkan sebelumnya dengan menurunnya skor pada item-item perilaku agresi yang melibatkan orang lain. Namun, hasil pengukuran menggunakan AQ-SF tidak dapat memastikan penurunan kecenderungan agresi partisipan karena kecenderungan faking good. Hal ini berkaitan dengan evaluasi alat ukur AQ-SF yang memiliki beberapa kerentanan terhadap respon faking dari partisipan, di antaranya bentuk alat ukur berupa self-report dan hanya melibatkan unfavorable item. Maka, penilaian penurunan kecenderungan agresi perlu dikaji pula dengan perbandingan pre dan post-test Grafis.

\section{Evaluasi Partisipan}

Sebelum menjalani terapi kelompok, beberapa partisipan dipengaruhi emosi negatif dalam menentukan solusi masalah dan melibatkan perilaku agresi sebagai salah satu cara merespon masalah. Selama mengikuti kegiatan sesi pada sesi ketujuh yang menuntut partisipan untuk mengaplikasikan cara kontrol amarah dan penyelesaian masalah yang tepat sesuai dengan kasus maupun berdasarkan pengalaman partisipan masing-masing, secara keseluruhan partisipan dapat menerapkan cara kontrol amarah dan penyelesaian masalah yang lebih positif dengan menghindari perilaku agresi. Hal ini merupakan perubahan yang lebih positif dibandingkan 
awal sesi. Secara umum, insight yang ditunjukkan partisipan memerlihatkan pemahaman mereka mengenai pentingnya kontrol amarah dan penyelesaian masalah yang tepat sebagai beberapa cara untuk menghindari agresi, yaitu dengan berpikir sebelum bertindak dan menyelesaikan masalah dengan tenang.

Berdasarkan evaluasi data secara keseluruhan, tidak semua partisipan memperlihatkan tipe agresi yang serupa, serta pemecahan masalah bukan merupakan masalah utama partisipan, sehingga intervensi problem solving skill training dinilai kurang tepat mengatasi masalah agresi partisipan. Di sisi lain, pelatihan problem solving menjadi edukasi baru yang positif dengan mengarahkan para partisipan untuk mampu menyelesaikan masalah dengan cara yang lebih tepat masalah. Selain itu, kegiatan kelompok selama intervensi mengarahkan partisipan semakin mampu untuk berinteraksi secara positif dengan banyaknya kegiatan yang mendorong mereka untuk bekerja sama. Hal ini mengarahkan pada penghayatan partisipan yang lebih positif terkait relasi sosial dan diri sendiri.

\section{KESIMPULAN DAN SARAN}

Intervensi kelompok yang dilakukan dengan menggunakan metode group anger management dan problem solving training dapat menurunkan kecenderungan perilaku agresi pada kelima partisipan. Penurunan perilaku agresi dapat dilihat dari hasil tes grafis Draw-A-Person, BAUM, alat ukur Skala Perilaku Agresi (AQ-SF), dan observasi yang dilakukan selama sesi intervensi berlangsung. Perubahan dalam tes grafis yang terjadi dapat dilihat dari perbandingan pre-test dan post-test hasil pengukuran AQ-SF serta tes Grafis. Perbandingan hasil pre-test dan post-test yang memperlihatkan penurunan skor agresi berdasarkan pengukuran AQ-SF. Namun, hasil pengukuran menggunakan AQ-SF tidak dapat memastikan penurunan kecenderungan agresi partisipan karena kecenderungan faking good.

\section{Saran untuk penelitian selanjutnya}

Beberapa saran yang dapat dipertimbangkan untuk penelitian selanjutnya, yaitu: (a) Mengelompokkan partisipan dengan tipe agresi yang serupa dalam satu kelompok terapi agar terapi yang diberikan lebih tepat sasaran sesuai kondisi partisipan; (b) Mempertimbangkan kesesuaian minat partisipan dengan jenis kegiatan yang dilakukan dalam terapi agar partisipan lebih terlibat aktif dalam kegiatan yang akan dilakukan selama terapi; (c) Mempertimbangkan penggunaan kata-kata dalam penyampaian materi yang mudah dipahami oleh partisipan; (d) Menambah sesi role play untuk membantu partisipan mampu mengaplikasikan teknik pengelolaan amarah dan pemecahan masalah yang tepat dalam konteks kehidupan sehari-hari; (e) Mengaitkan situasi dan contoh yang dibahas dalam proses terapi dengan kondisi partisipan agar membantu partisipan lebih mudah memahami penjelasan yang diberikan; (f) Mempertimbangkan faktor eksternal yang dapat mempengaruhi proses terapi agar memastikan kondisi yang kondusif selama terapi, seperti tempat, waktu, dan durasi pelaksanaan terapi.

\section{Ucapan Terima Kasih (Acknowledgement)}

Peneliti berterima kasih kepada kelima partisipan dan pihak dari LPKA TNG yang terlibat dan bekerja sama dengan peneliti selama proses penelitian dilakukan. Selain itu, peneliti juga berterima kasih kepada pihak-pihak yang telah membantu peneliti dalam memberikan umpan balik dan masukan yang membangun serta bermanfaat dalam menyusun penelitian ini. 


\section{REFERENSI}

Babore, A., Carlucci, L., Cataldi, F., Phares, V., \& Trumello, C. (2017). Aggressive behaviour in adolescence: Links with self-esteem and parental emotional availability. Social Development, 26(4), 740-752.

Friedberg, R. D., \& Brelsford, G. M. (2013). Training methods in cognitive behavioral therapy: tradition and invention. Journal of Cognitive Psychotherapy, 27(1), 19-29.

Bryan, F., \& Smith, B. (2011). Refining the architecture of aggression: A measurement model for the Buss Perry aggression questionnaire. Journal of Research in Personality 35, 138-167.

Cattell, R. (1979). Are culture fair intelligence tests possible and necessary? Journal of Research and Development in Education, 2, 2-13.

Cillessen, A., Lansu., \& Berg, Y. (2014). Aggression, hostile attributions, status, and gender: A continued quest. Development and Psychopathology, 26, 635-644.

Connor, D.F., Steingard, R.J., Cunningham, J.A., Anderson, J.J., \& Melloni, R.H. (2004). American Journal of Orthopsychiatry, 74(2), 129-136.

Down, R., Willner, P., Watts, L., \& Griffiths, J. (2010). Anger management groups for adolescents: A mixed-methods study of efficacy and treatment preferences. Clinical Child Psychology and Psychiatry, 16(1), 33-52.

Estévez, E., Jiménez, T.I., \& Moreno, D. Aggressive behavior in adolescence as a predictor of personal, family, and school adjustment problems. Psicothema, 30(1), 66-73.

Faris, R., \& Ennett, S. (2012). Adolescent aggression: the role of peer group status motives, peer aggression, and group characteristics. Social Networks, 34(4), 371-378.

Irena, F. (2014). Penerapan solution focused brief therapy untuk menurunkan tingkat agresivitas remaja di lembaga permasyarakatan anak pria Tangerang. Masters thesis, Universitas Tarumanagara.

Kartono, K. (2011). Patologi Sosial. Jakarta: PT. Raja Grafindo Persada.

Krahe, B. (2013). The Social Psychology of Aggression. (ed 2). London: Psychology Press.

Liu, J., Lewis, G., \& Evans, L. (2012). Understanding aggressive behavior across the life span. Journal Psychiatry Mental Health Nursing, 20(2): 156-168.

Löka, N., Bademlib, K., \& Canbaz, M. (2017). The effects of anger management education on adolescents' manner of displaying anger and self-esteem: a randomized controlled trial. Archives of Psychiatric Nursing, 32, 75-81.

Machover, K. (1949). Personality projection in the drawing of the human figure. Illanois: Charles C Thomas.

Merrill, K. L., Smith, S. W., Cumming, M. M., \& Daunic, A. P. (2016). A review of social problem-solving interventions. Review of Educational Research, 87(1), 71-102.

Mirzaei, R., Meimandi, N.I., Mousavi, E., Raesi, Z., \& Masoudi, S. (2016). Effectiveness of training problem solving and anger management on improve of problem solving ability and aggression control ability in prisoners. Journal of Applied Environment Biological Science, $6(5), 167-172$.

Nenty, H. J., \& Dinero, T. E. (1981). A cross-cultural analysis of the fairness of the Cattell Culture Fair Intelligence Test using the rasch model. Applied Psychological Measurement, 5(3), 355-368.

Ogdon, D. (1974). Psychodiagnostics and personality assessment: A handbook (2nd Ed.). Los Angeles: Western Psychological Services.

Papalia, D. E., \& Martorell, G. (2014). Human development (13 ${ }^{\text {th }}$ ed.). New York: McGraw-Hill. Santrock, J.W. (2011). Life Span Development, (13 ${ }^{\text {th }}$ ed.). New York: McGraw-Hill Education.

Silva, R.J., Soares, N.M.M., \& Oliveira, A.C.C. (2014). Factors associated with violent behavior among adolescents in northeastern Brazil. The Scientific World Journal, 1-7. 